\title{
Sınır Elemanları Yöntemiyle MEMS Plakası Dışında Oluşan Manyetostatik Potansiyel Analizi
}

\author{
Ramazan SOLMAZ ${ }^{1 *}$, Fevzi HANSU ${ }^{2}$ \\ ${ }^{1}$ Siirt Üniversitesi, Fen Bilimleri Enstitüsü, Elektrik Elektronik Mühendisliği Anabilim Dalı, Siirt. \\ ${ }^{2}$ Siirt Üniversitesi, Mühendislik Fakültesi, Elektrik Elektronik Mühendisliği Bölümü, Siirt. \\ 1*Sorumlu yazar e-posta: rsolmaz23@gmail.com ID: http://orcid.org/0000-0001-8933-2922 \\ 2e-posta:f_hansu@hotmail.com ID: http://orcid.org/0000-0002-5325-5459 \\ Geliş Tarihi: 18.07.2019 Kabul Tarihi: 15.04.2020
}

\begin{tabular}{|c|c|}
\hline & ठेz \\
\hline $\begin{array}{c}\text { Anahtar kelimeler } \\
\text { Sınır elemanları } \\
\text { metodu; MEMS; } \\
\text { NEMS; } \\
\text { Manyetostatik } \\
\text { potansiyel }\end{array}$ & $\begin{array}{l}\text { MEMS ve NEMS cihazlarının, gittikçe küçülen yapılarıyla beraber kararlı ve verimli çalışabilmesi için } \\
\text { tasarımları önem kazanmaktadır. Sınır elemanları yöntemi bu tür cihazların tasarımı için son zamanlarda } \\
\text { yaygın olarak kullanılan bir yöntemdir. Bu çalışmada, klasik yöntemler olarak ifade edilen sonlu farklar } \\
\text { yöntemi ve sonlu elemanlar yöntemine göre daha yeni bir metot olan sınır elemanları metodu } \\
\text { araştırılmışır. Sınır elemanları yönteminin MEMS tasarımındaki performansını incelemek için MEMS } \\
\text { plakası dışında oluşan skaler manyetik potansiyel analiz edilmiştir. Illk olarak problem bölgesi sınırları, sabit } \\
\text { sınır elemanı ile bölümlenmiş ve Dirichlet sınır şartları tanımlanarak problem modellenmiştir. Problemi } \\
\text { çözmek için Matlab ortamında yeni bir program geliştirilmiştir. Tasarlanan program, limitleri ve eleman } \\
\text { sayıları belirlenen iki boyutlu problem bölgesinde, otomatik olarak sonlu elemanlar yöntemi ve sınır } \\
\text { elamanları yöntemi için çözüm yapmaktadır. Sonuçların doğruluk derecesini kontrol etmek için problem } \\
\text { analitik olarak çözülerek tüm sonuçlar karşılaştııımıştır. Uygulamada elde edilen sonuçlara göre sınır } \\
\text { elemanları yönteminin sonlu elemanlar yöntemine göre problem çözmek için gerekli veriler, uygulama } \\
\text { kolaylığı ve sonuçların doğruluğu açısından birçok pozitif yöne sahip olduğu ifade edilebilir. Bu çalışmada } \\
\text { elde edilen sonuçlara göre MEMS ve NEMS cihazların elektrostatik ve manyetostatik algılama mesafeleri } \\
\text { tespitinde sınır elamanları metodunun kullanılması önerilebilir. Geliştirilen yeni program, bu tür cihazların } \\
\text { daha iyi bir tasarıma sahip olmalarına katkı sunabilir. }\end{array}$ \\
\hline
\end{tabular}

\section{Magnetostatic Potential Analysis Outside MEMS Plate by Boundary Element Method}

Keywords

Boundary element method; MEMS;

NEMS;

Magnetostatic potential

\begin{abstract}
Designs of MEMS and NEMS devices are gaining importance for their stable and efficient operation with their shrinking structures. Boundary element method is a widely used method for design of such devices, recently. In this study, finite difference method, which is expressed as classical methods, and boundary element method, which is a newer method compared to finite element method, was investigated. To examine the performance of boundary element method in MEMS design, the scalar magnetic potential formed outside the MEMS plate was analyzed. Firstly, the boundaries of problem region are divided with a fixed boundary element and the problem is modeled by defining Dirichlet boundary conditions. A new program has been developed in Matlab environment to solve the problem. The designed program automatically solves the finite element method and the boundary element method in two-dimensional problem region whose limits and number of elements are determined. To check the accuracy of the results, the problem was solved analytically and all results were compared. According to the results obtained in the application, it can be stated that boundary element method has many positive aspects in terms of the data required for problem solving, the ease of application and the accuracy of the results according to the finite element method. According to the results obtained in this study, it may be suggested to use the boundary element method in detection of electrostatic and magnetostatic sensing distances of MEMS and NEMS devices. The developed program can contribute to better design of such devices.
\end{abstract}

(C) Afyon Kocatepe Üniversitesi 


\section{Giriş}

Yaşam kalitesini artırmak için yapılan çalışmalar sayesinde teknolojinin uygulanma alanı küçük ve ince duvarlı yapılara doğru sürekli genişlemektedir. $\mathrm{Bu}$ sayede istenen özelliklere sahip veya istenen görevleri yerine getirebilecek nanometre boyutlarında malzeme üretimi ile Mikro-ElektroMekanik (MEMS) veya Nano-Elektro-Mekanik Sistemler (NEMS) üretilebilmektedir. MEMS ve NEMS cihazların gittikçe küçülen yapılarıyla beraber kararlı ve verimli çalışabilmesi için tasarımları önem kazanmaktadır.

Mikro-Elektro-Mekanik Sistemler (MEMS), mikroelektro-mekanik, mikro-akışkan, mikro-optoelektro-mekanik ve mikro-termo-mekanik cihazları ve sistemleri kapsayan sabit veya hareketli mikro yapıları içeren çok geniş alana sahiptirler (Jog and Kunal 2016).

Elektrostatik veya manyetostatik harekete geçirme, imalat sürecinin basitliği, uygun ölçekleme yasaları, büyük kuvvetler geliştirme kabiliyeti, düşük güç tüketimi ve standart bir entegre devre ortamıla entegrasyon imkânı nedeniyle çeşitli MEMS'ler üretilmektedir. Bu tür MEMS cihazların mikro sensörler, mikro-aktüatörler, mikro jetler, mikro hoparlörler, anahtarlar, mikro aynalar, ivmeölçerler, basınç sensörleri, mikro pompalar, hareketli valfler, günümüzde otomotiv elektroniği, tıbbi cihazlar, taşınabilir akıllı elektronik, sabit disk sürücüleri, bilgisayar çevre birimleri vb. uygulamaları bulmaktadır (Zhang et al. 2014, Zozulya and Saez 2014, Ding et al. 2017). Bu küçük ve ince yapılı cihazların doğru, verimli ve kararlı bir şekilde çalışabilmeleri için iyi bir tasarıma sahip olmaları gerekmektedir.

Mikro mekanik yapılar doğal olarak üç boyutlu olup analitik analiz için geometrik olarak çok karmaşıktırlar. Bu nedenle sayısal bir yaklaşıma ihtiyaç duyulmaktadır. MEMS'teki mekanik dağılımı, elektrik veya manyetik alan dağılımını öngörmek için sınır integral denklemi (Boundary Integral EquationBIE) ideal bir uygulama olabilir (Frangi 2009, Rodriguez et al. 2015).

Elektrikle çalıştırılan MEMS cihazlarının sayısal simülasyonunda, 1990 yılı başlarından beri çok ince iletken plakaların dışındaki alan analizi için sınır elemanı yöntemi kullanılmaktadır. Kalınlıkları ihmal edilmiş her plakanın üst ve alt yüzeyindeki yüklerin toplamını bulmak için zayıf tekil çekirdekli standart sınır integral denklemi kullanılmaktadır (Mukherjee et al. 2005, Eshraghia and Dag 2018).

Sınır elemanları metodu (SEM, Boundary Element Method-BEM) yaklaşık olarak son 20 yılda elektrik mühendisliği ve özellikle elektromanyetikte farklı problemleri çözmek için yaygın olarak kullanılan köklü bir teknik haline gelmiştir. Yöntem, klasik sınır integral denklemi yöntemlerinin ve kısmi diferansiyel denklemlerin çözümü için sonlu elemanlar yönteminden (Finite Element MethodFEM) türetilen sayısal tasarımların bir kombinasyonu olarak düşünülebilir. SEM, FEM ayrıklaştırma kavramlarını kullanarak integral denklemlerini çözmek için gelişmiş uygun sayısal bir araç haline gelmiştir. Sınır elemanları yöntemi (SEM) yaygın olarak kullanılan köklü iki sayısal yönteme, yani sonlu farklar (FDM) ve sonlu elemanlar (FEM) yöntemlerine göre yeni bir metottur (Patridge et al. 1992, Brebbia and Poljak 2005).

Bu çalışmamızda MEMS plakası dışında oluşan manyetostatik alan dağılımının sınır elemanları metoduyla analiz edilmesiyle elde edilen sonuçlar, aynı problem için sonlu elemanlar ve analitik çözüm yöntemleri kullanılarak elde edilen sonuçlarla karşılaştırılmıştır.

\section{Metot}

\subsection{Elektromanyetik potansiyel}

Tüm elektromanyetik olayların analizinde Maxwell denklemleri temel oluşturmaktadır. Elektrik ve manyetik alanların matematiksel olarak ifade edilmesi, alanlar yerine yardımcı potansiyel fonksiyonlar kullanılarak basitleştirilebilir. Bu yardımcı fonksiyonlar, elektriksel skaler potansiyeli $\varphi$, manyetik vektör potansiyeli $A$ ve manyetik skaler potansiyel $\varphi_{m}{ }^{\prime}$ dir. $\mathrm{Bu}$ potansiyeller doğrudan Maxwell denklemlerinden türetilmektedir (Patridge et al. 1992, Brebbia and Poljak 2005).

Bir $f$ vektörü için bilinen vektör özdeşliği dikkate alınırsa;

$\nabla x \nabla x f=0$

bu, iki kere türevlenebilir vektör $f$ için geçerlidir. Akım yoğunluğu $B$, bir yardımcı vektör $A$ vasıtasıyla ifade edilirse Maxwell manyetik diverjans denklemi $(\nabla B=0)$ her zaman sağlanabilir.

$B=\nabla x A$ 
ilk Maxwell denklemi olan Eşitlik 3, Faraday yasasının diferansiyel formu olup zamanla değişen manyetik akı yoğunluğu $B, E$ elektrik alanının curl'ünü verir.

$\nabla x E=-\frac{\partial}{\partial t}(\nabla x A)$

Bu denklem düzenlenirse Eşitlik 4 elde edilir (10).

$\nabla x\left(E+\frac{\partial A}{\partial t}\right)=0$

Herhangi bir türevlenebilir skaler fonksiyon $V^{\prime}$ nin gradyanın curl'ü, her zaman sıfır olduğu için,

$\nabla x \nabla V=0$

Eşitlik 4 'te parantez içindeki terim, skaler potansiyel fonksiyon $\varphi$ 'inin gradyanı olarak yazılabilir;

$E+\frac{\partial A}{\partial t}=-\nabla \varphi$

veya

$E=-\frac{\partial A}{\partial t}-\nabla \varphi$

$A$ ve $\varphi$ genellikle manyetik vektör potansiyeli ve elektrik skaler potansiyeli olarak ifade edilir. Böylece, potansiyel fonksiyonları $A$ ve $\varphi$, manyetik ve elektrik alanı Eşitlik 1 ve Eşitlik 6 'dan belirlenebilir. Elektrik akımından bağımsız olan $(j=0)$, manyetik alanların var olmasından dolayı birçok manyetostatik problemler vardır. Bu tür kaynaktan bağımsız alanlar için, manyetik alan $H^{\prime} ı n$ curl'ü sıfıra eşittir.

$\nabla \mathrm{x} H=0$

Herhangi bir sıfır-curl vektörü, bir skaler fonksiyonunun gradyanı cinsinden temsil edilebildiğinden, bu tür durumlarda manyetik alan şiddeti şu şekilde yazılabilir;

$H=-\nabla \varphi_{m}$

Burada elektrostatik potansiyel ile uygun bir benzetme sağlamak için eksi işaret alınır. Bu durum, elektrostatikteki $E=-\nabla V$ eşitliğine benzer şekilde, $V_{m}$ ile gösterilen ve negatif gradyantı manyetik alan şiddetini veren bir manyetostatik potansiyelin tanımlanabileceği anlamına gelir.

$H=-\nabla V_{m}$
$\mathrm{Bu}$ sonucun doğruluğunu kontrol etmek için Eşitlik 10'da tanımlanan manyetik alan şiddeti Eşitlik 8'de yerine yazılırsa,

$\nabla \mathrm{x} H=\mathrm{J}=-\nabla \mathrm{x}\left(\nabla V_{m}\right)=0$

elde edilir. Eşitlik $11^{\prime}$ in sağ tarafındaki manyetostatik potansiyelin gradyanının curl'ü sıfır olduğundan, akım yoğunluğu sıfır olur. Böylece Eşitlik 8 sağlanmış olur.

Manyetik malzeme lineer ve homojen ( $B=\mu H$ ve manyetik geçirgenliği sabit) kabul edilirse, Eşitlik 8 ve Eşitlik 10'dan manyetostatik potansiyel için,

$\nabla B=\mu \nabla H=0$

$\nabla B=\mu \nabla\left(-\nabla V_{m}\right)=0$

$\nabla^{2} V_{m}=0 \quad(J=0)$

Laplace denklemi elde edilir. Burada manyetostatik potansiyel $V_{m}$, akım yoğunluğunun sıfır olduğu bölgede ve homojen manyetik malzemede her zaman Eşitlik 14'teki Laplace denklemini sağlar. $V_{m}{ }^{\prime}$ in birimi Amper-sarım'dır. Laplace denkleminin çözümünden edilen manyetostatik potansiyel değeri kullanılarak manyetik alan şiddeti hesaplanabilir (Patridge et al. 1992, Brebbia and Poljak 2005, Matthew 2001, Gürdal 2015, Dorfmann and Ogden 2014).

\subsection{Laplace denklemi için sınır elemanları yöntemi}

Sınır elemanları yöntemi (SEM) ile bir problem çözülürken ilk olarak problemin sınır integral ifadesinin elde edilmesi gerekmektedir.

$\nabla^{2} V_{m}=0$

$V_{m}$, manyetik skaler potansiyel olmak üzere Eşitlik $15^{\prime}$ te ifade edilen Laplace denkleminden bir sınır integral denklemi türetmek için, ağırlıklı artıklar metodu ya da ikinci Green özdeşliğinden biri tercih edilebilir. Bu Laplace denkleminden türetilen sınır integral denklemi şu şekildedir.

$c_{i} V_{i}+\int_{S} V_{m} q^{*} d S=\int_{S} q V_{m}{ }^{*} d S$

Burada $V_{m}{ }^{*}$, Eşitlik $15^{\prime}$ in temel çözümü, $q^{*}$ ise bu çözümün normale göre türevidir. Temel çözüm olan $V_{m}{ }^{*}$, bir "i" noktasında yer alan yoğunlaştırımış birim kaynağın oluşturduğu alanı ifade eder. Kaynağın meydana getirdiği etki, problem sınırında herhangi bir sınır koşulu tanımlanmamış ise sonsuza 
gider. Bu durum Eşitlik 17'deki Poisson denklemi ile ifade edilebilir.

$\nabla^{2} V_{m}^{*}+\Delta_{i}=0$

Bu denklemin çözülmesiyle, temel çözüm elde edilir. $\Delta_{i}$ Dirac delta fonksiyonu olup bu fonksiyon $x=x_{i}$ noktasında sonsuza giderken, bu nokta dışındaki yerlerde sıfırdır. $V_{m}{ }^{*}$ temel çözümü, iki boyutlu problemlerde aşăı̆ıaki gibidir.

$V_{m}{ }^{*}=\frac{1}{2 \pi} \ln \left(\frac{1}{r}\right)$

Burada $r$, kaynağın bulunduğu nokta ile temel çözümün uygulandığı "i" düğümü arasındaki mesafedir. Düğüm, çözümün sınırda uygulandığı noktalara denir. Bu yöntemde, Eşitlik 18'de verilen denklem tüm " $i$ " düğümlerine uygulanır ve her düğümün diğer düğümlere olan etkisiyle sınırda bilinmeyenler bulunur.

Sınır elemanı yönteminde iki boyutlu bir problem sınırı N parçaya bölünür. Her bir sınır parçası sabit, lineer veya eğrisel eleman olarak ifade edilir. Çözüm, sabit eleman, lineer eleman veya eğrisel elaman seçilerek gerçekleştirilir. Kullanılan sınır elemanı tipi sabit eleman ise elemanların orta noktası düğüm olarak alınır ve eleman boyunca gerilim değeri sabit kabul edilir.

Eşitlik 16, sınır koşulları tanımlanmadan önce bir " $i "$ kaynak noktası için aşağıdaki gibi ayrıştırılabilir.

$c_{i} V_{i}+\sum_{j=1}^{N} \int_{S_{j}} V_{m} q^{*} d S=\sum_{j=1}^{N} \int_{S_{j}} q V_{m}{ }^{*} d S$

(Burada, "i" sınırdaki düğümü, "j" ise sınır elemanlarını temsil etmektedir.) " $i " 1$ 'den $N$ 'e kadar (düğüm sayısı) değişmekte ve Eşitlik $18^{\prime}$ de verilen temel çözüm sırasıyla her bir "i" düğümü ve sınır elmanı için gerçekleştirilirse Eşitlik 20'de verilen matris formundaki denklem sistemi elde edilir.

$[H]\left[V_{m}\right]=[G][q]$

Problem alanı tanımlanırken belirlenen sınır koşulları Eşitlik 20'ye uygulanır ve bu eşitlikte bilinmeyenler bir tarafa toplanırsa Eşitlik 21 elde edilir.

$\mathrm{Ax}=\mathrm{y}$

Eşitlik 21'in çözümüyle problem sınııındaki tüm bilinmeyen bulunur. Sınır elemanları metodunda sınır değerleri bilinen problemde sınııın iç tarafında kalan herhangi bir iç nokta için Eşitlik 22 kullanılarak manyetik skaler potansiyel değeri hesaplanabilir (Patridge et al. 1992, Brebbia and Poljak 2005, Yıldırım 1999).

$V_{i}=\int_{S} q V_{m}^{*} d S-\int_{S} V_{m} q^{*} d S$

\section{Bulgular ve Tartışma}

Uygulamada, MEMS plakası dışında oluşan manyetostatik alan dağılımını hesaplamak için problem bölgesi Şekil 1'deki gibi temsil edilmiştir. Alan analizi sınır elemanları metodu ve sonlu elemanlar metodu kullanılarak gerçekleştirilmiştir. Sonuçları karşılaştırmak için problem analitik olarak çözülmüştür.

Sınır elemanları yöntemi ile çözüm için problem bölgesinin sınırları sabit sınır elemanları ile bölümlendikten sonra sınır şartları tanımlanmıştır. Şekil 1'de gösterildiği gibi, Dirichlet sınırları için $y=b$ sınırında $V_{m}=20(A-s)$ diğer sınırlarda $V_{m}=0(A-s)$ olarak tanımlanmıştır. Tanımlanan sınır şartları uygulanarak problem modellenmiştir. Daha sonra Matlab'da yazılan program ile manyetostatik potansiyel değerleri iki ayrı uygulama için hesaplanmıştır.

Sonlu elemanlar yöntemi ile çözüm, Şekil 1'de gösterilen problem alanı üçgen elemanlar ile bölümlendikten sonra, Dirichlet sınırları için $y=b$ sınırında $V_{m}=20(A-s)$, diğer sınırlarda $V_{m}=0(A-s)$ sınır şartları tanımlanarak modellenmiştir. Modellenen bu problem Matlab'da yazılan program ile çözülerek sonlu elemanlar metodunun sonuçları elde edilmiştir.

Yöntemlerin doğruluk derecelerini belirlemek için aynı problemin analitik çözümü yapıımıştır. Analitik çözüm sonuçları Eşitlik 23'te verilen denklem kullanılarak elde edilmiştir.

$$
V(x, y)=\frac{4 V_{m}}{\pi} \sum_{k=1}^{\infty} \frac{\sin \frac{n \pi x}{a} \sinh \frac{n \pi y}{a}}{n \sinh \frac{n \pi b}{a}}, \quad 2 k-1
$$




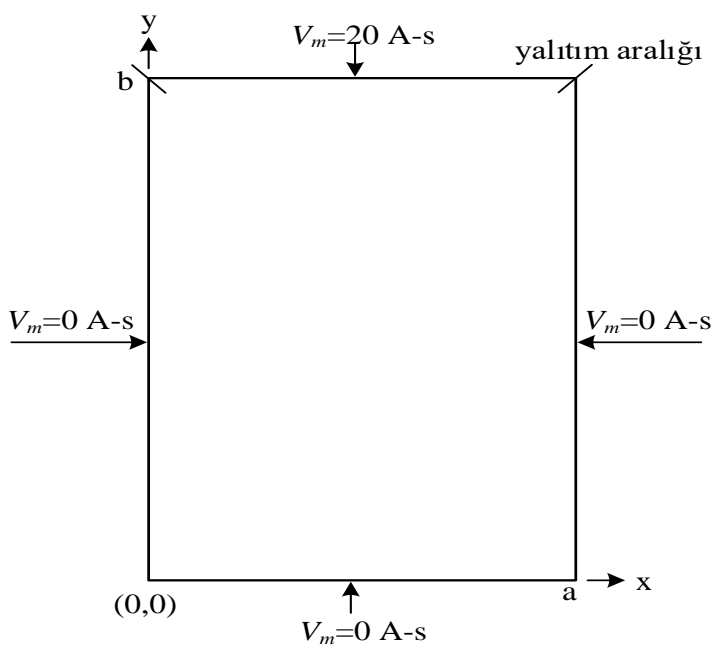

Şekil 1. MEMS plakası dışında oluşan manyetostatik problem alanı.

Şekil 1'de gösterilen alan için iki farklı uygulama yapılmıştır. Burada $a=1, b=2$ ve $a=1, b=1$ birim olmak üzere ve sınır şartları aynı olmak kaydıyla yapılan hesaplamada elde edilen sonuçlar Çizelge 1 ve Çizelge 2'de verilmiştir. Burada değişen problem bölgesi için yöntemlerin doğruluk derecesi analiz edilmiştir. Sınır elemanları ve sonlu elemanlar metodunda kullanılan elemanların boyları eşit olacak şekilde problem modellenmiştir. Sınır elemanlar yönteminde sabit eleman boyu 0,1 birim ve sonlu elemanlar yönteminde üçgen elemanın dik kenar boyu 0,1 birimdir. Birinci uygulamada sınır elemanları yönteminin sabit eleman sayısı 60 adet, ikinci uygulama için 40 elemandır. Sonlu elemanlar yönteminde birinci uygulama için 400 üçgen eleman ikinci uygulama için 200 üçgen eleman ile problem temsil edilmiştir. Çizelge 1 ve 2 'de verilen süreler, yöntemlerin bir uygulama için tüm aşamalarına ait işlem sürelerini kapsamaktadır. Çizelgelerde verilen değerler yapılan uygulamadan alınmış bazı noktalar için örneklerdir.

Çizelge 1. Şekil 1 'de verilen $a=1, b=2$ ve $V_{m}=20$ A-s değerleri için, SEM sonuçlarının analitik ve FEM sonuçlarıyla karşılaştırılması ( $\mathrm{x}=0,5$ için).

\begin{tabular}{|c|c|c|c|c|c|}
\hline$y$ & $\begin{array}{c}\text { SEM } \\
\text { (60 Eleman) } \\
0,08 s\end{array}$ & $\begin{array}{c}\text { FEM } \\
\text { (400 Eleman) } \\
24,75 s\end{array}$ & $\begin{array}{c}\text { Analitik Sonuç } \\
0,0035 s\end{array}$ & $\begin{array}{c}\text { SEM Hata } \\
\text { (\%) }\end{array}$ & $\begin{array}{c}\text { FEM Hata } \\
\text { (\%) }\end{array}$ \\
\hline 1,9 & 16,06771 & 16,00784 & 16,06416 & 0,02211 & $-0,35186$ \\
\hline 1,5 & 5,218634 & 5,225264 & 5,218867 & $-0,00446$ & 0,122434 \\
\hline 1,3 & 2,811224 & 2,834172 & 2,811794 & $-0,02026$ & 0,789569 \\
\hline 1 & 1,097293 & 1,116205 & 1,097698 & $-0,03695$ & 1,658017 \\
\hline 0,7 & 0,423272 & 0,433925 & 0,423483 & $-0,04996$ & 2,406372 \\
\hline 0,1 & 0,030369 & 0,031434 & 0,030373 & $-0,01412$ & 3,376574 \\
\hline
\end{tabular}

Illk uygulamada Şekil 1'de gösterilen problemin iç bölgesinde $x=0,1 \ldots 0,9$ ve $y=0,1 \ldots 1,9$ noktaları için manyetostatik potansiyel hesaplanmıştır.

$\mathrm{Bu}$ uygulamada sınır elemanları metodu için problem bölgesi sınırları 60 adet sabit sınır elemanı ile temsil edilerek problem modellenmiştir. Daha sonra Dirichlet sınır şartları ve sabit sınır elemanları koordinatları belirlenmiştir. Matlab R2014a programında $0,08 s$ işlem süresi ile problem çözülmüştür. illk olarak sınırda bilinmeyen $q$ değerleri hesaplanmış daha sonra Çizelge 1 'de iç bölgede bulunun noktalar için manyetostatik potansiyel analiz sonuçları elde edilmiştir.

Sonlu elemanlar metodu ile aynı Dirichlet sınırlar için yapılan uygulamada, problem bölgesi 400 üçgen eleman ile modellenerek problem Matlab R2014a programında ortalama 24,75 s işlem süresiyle çözülmüştür. Çizelge 1'de verilen bazı noktalar için sonlu elemanlar metoduna ait sonuçlar verilmiştir. Eşitlik 23'te verilen denklem kullanılarak
Çizelge 1'deki analitik sonuçlar elde edilmiştir. Çizelge 1'deki analitik sonuçlar referans alınarak incelendiğinde sınır elemanları yöntemi sonuçları çok kısa işlem süresi ve ihmal edilebilir hata ile elde edilmiştir. Sonlu elemanlar metodu ile yapılan çözümde ise yaklaşık 300 kat daha fazla bir zaman harcanarak $x=0,5$ ve $y=1,9$ noktasından $y=0,1$ noktasına giderek artan bir hata ile sonuçlar elde edilmiştir.

Literatürde sınır elemanları ile sonlu elemanların kombinasyonunun daha iyi sonuç verdiği ifade edilmektedir. Çizelge 1'deki hatalar incelendiğinde sınır elemanlarının hatasının negatif olduğu noktalarda sonlu elemanlar yönteminin hatasının pozitif, yine sınır elemanları hatasının pozitif olduğu noktalarda sonlu elemanlar yöntemi hatasının negatif olduğu görülmektedir. 
Çizelge 2. Şekil 1'de verilen $a=1, b=1$ ve $V_{m}=20$ A-s değerleri için, SEM sonuçlarının analitik ve FEM sonuçlarıyla karşılaştırılması ( $\mathrm{x}=0,5$ için).

\begin{tabular}{|c|c|c|c|c|c|}
\hline$y$ & $\begin{array}{c}\text { SEM } \\
\text { (40 Eleman) } \\
0,046 s\end{array}$ & $\begin{array}{c}\text { FEM } \\
\text { (200 Eleman) } \\
3,14 s \\
\end{array}$ & $\begin{array}{c}\text { Analitik Sonuç } \\
0,003 s\end{array}$ & SEM Hata (\%) & FEM Hata (\%) \\
\hline 0,9 & 16,03736 & 15,9764 & 16,03379 & 0,022275 & $-0,3592$ \\
\hline 0,7 & 9,359611 & 9,311914 & 9,358044 & 0,016735 & $-0,49539$ \\
\hline 0,5 & 5 & 5 & 5 & 1E-08 & $-3,9 \mathrm{E}-07$ \\
\hline 0,2 & 1,474019 & 1,483906 & 1,474017 & 0,000123 & 0,666399 \\
\hline 0,1 & 0,702907 & 0,708133 & 0,70268 & 0,032313 & 0,770118 \\
\hline
\end{tabular}

İkinci uygulamada ise $a=1$ ve $b=1$ birim için yöntemlerin manyetik skaler potansiyel dağılımı incelenmiştir. Burada hesaplama $x=0,1 \ldots 0,9$ ve $y=0,1 \ldots 0,9$ noktaları için yapılmıştır.

Uygulamada sınır elemanları yöntemi için problem sınırı 40 adet sabit sınır elemanı ile temsil edilmiştir. Yapılan çözümde $x=0,5$ noktası ve $0,1 \leq y \geq 0,9$ değerleri için iç noktalarda elde edilen değerler, analitik çözümden elde edilen değerler ile karşılaştırılmıştır. Bu noktalar için sınır elemanlarına ait sonuçlar küçük hatalar ile elde edilmiştir. Sınır elemanları yönteminin sonuçları incelendiğinde,
Çizelge 1 ve Çizelge 2'de görüldüğü gibi, değişen problem bölgesi için hata oranlarının birbirilerine yakın olduğu görülmüştür. $\mathrm{Bu}$ da yöntemin potansiyel analizinde kararlı olduğunu göstermektedir.

Sonlu elemanlar yöntemi ile yapılan çözümde 200 üçgen eleman kullanılmıştır. Bu çözümde eleman sayısı \%50 azalmasına karşın işlem süresi yaklaşık olarak sekiz kat azalmıştır. Daha büyük problem bölgesi için işlem yükü artacağından problemin çözümü daha çok zaman alacaktır. Bu uygulamada elde edilen hata oranları ilk uygulamaya göre yaklaşık olarak \%60 oranında azalmıştır.
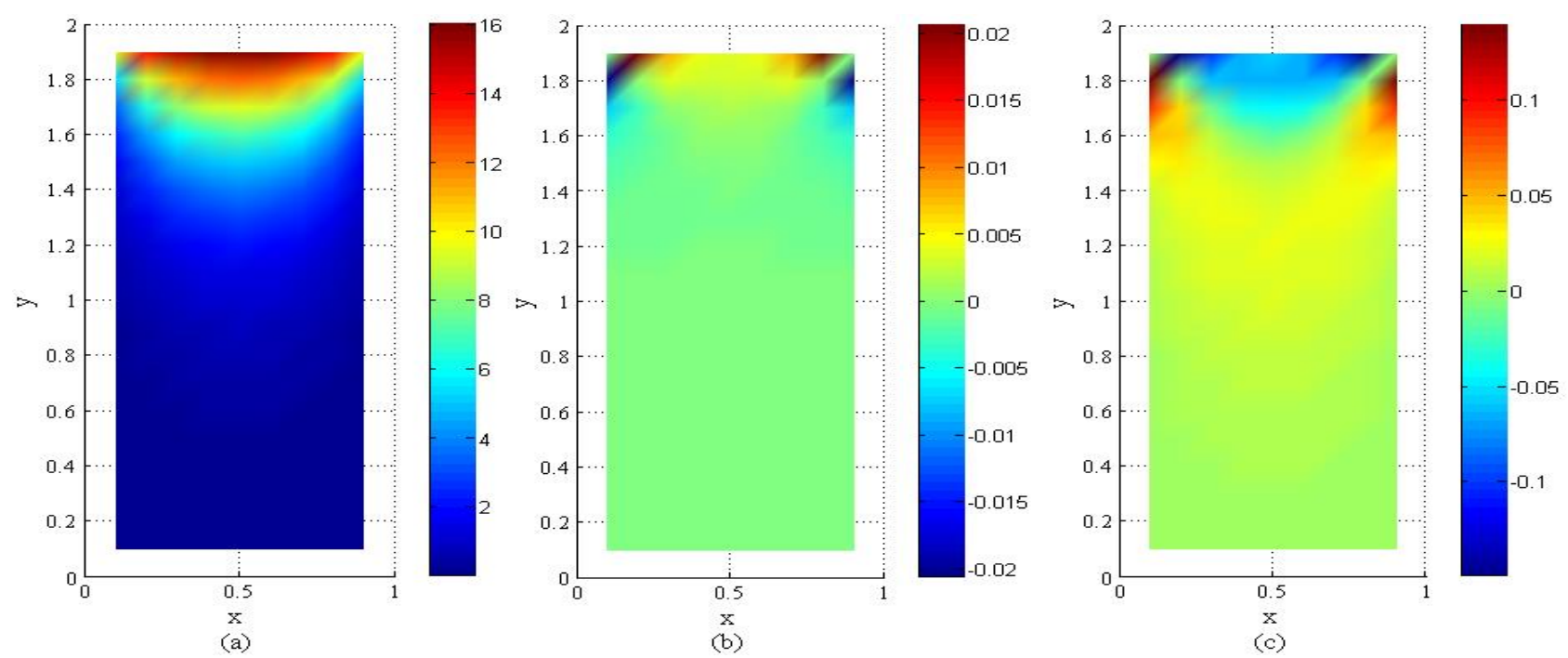

Şekil 2. Şekil $1^{\prime}$ de $a=1, b=2$ ve $V_{m}=20$ A-s için iç noktalardaki manyetostatik potansiyel dağılımı, a) Sınır elemanları metodu manyetostatik potansiyel dağılımı, b) SEM'in analitik sonuçlara göre fark dağılımı, c) FEM'in analitik sonuçlara göre fark dağılımı.

Şekil 2a sınır elemanları yöntemi ile $a=1$ ve $b=2$ problem alanı için yapılan hesaplamada manyetostatik potansiyel dağılımını göstermektedir. Şekil $2 b^{\prime}$ de sınır elemanları ile analitik çözümden elde edilen manyetostatik potansiyel dağılımların farkı gösterilmektedir.
Şekil 2c'de sonlu elemanlar ile analitik çözümden elde edilen manyetostatik potansiyel dağılımların farkı gösterilmektedir. Şekil $2 b$ ve $2 c$ karşılaştıııldığında Şekil $2 b^{\prime}$ deki fark dağııımı $y \leq 1,2$ noktaları için sıfıra yakın olup Şekil $2 c^{\prime}$ de ise $y \leq 0,3$ noktalarında fark dağılımı sıfıra yaklaşmıştır. 

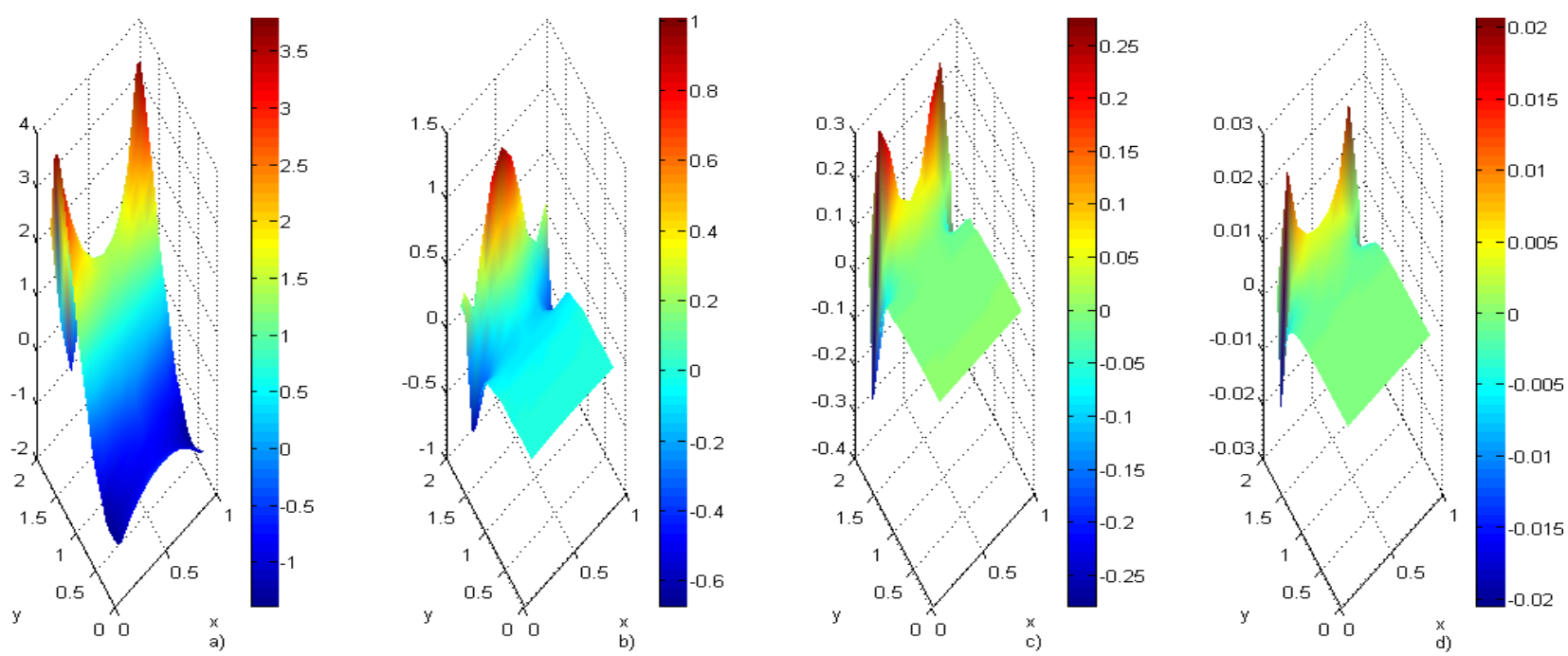

Şekil 3. Şekil $1^{\prime}$ de $a=1, b=2$ ve $V_{m}=20$ A-s için SEM'in analitik sonuçlara göre iç noktalardaki manyetostatik potansiyel hata dağılımı, a) Dört eleman ve 0,0012 s işlem süresi, b) On iki eleman ve 0,0173 s işlem süresi, c) Yirmi dört eleman ve 0,0263 s işlem süresi, d) Altmış eleman ve 0,0534 $s$ işlem süresi.

Sınır elemanları yöntemi ile yapılan uygulamada sınır eleman sayısının sonuçlara etkisini görmek için Şekil 3'te görüldüğü gibi 4, 12, 24 ve 60 sabit sınır elemanı ile ayrı ayrı çözüm yapılmıştır. İşlem süresi sirasiyla $0,0012 s, 0,0173 s, 0,0236 s$ ve $0,0534 s$ olmuştur. Sonuçlar incelendiğinde eleman sayısı arttıkça işlem süreleri yaklaşık iki katına çıkmıştır. Manyetostatik potansiyelin hata dağılımı eleman sayısı arttıkça düşmüş, Şekil 3d'de sıfıra yaklaşmıştır.

Sonlu elemanlar metodu ile yapılan çözümde $y=0$ noktasına yaklaşıldıkça analitik sonuçlara göre hatanın arttığı görülmektedir. Sınır elemanları metodunda aynı durum geçerli değildir. Her iki yöntemin işlem süreleri ve kullanılan eleman sayıları göz önüne alındığında sonlu elemanlar yönteminin işlem süresinin daha çok azaldığı görülmektedir. Daha büyük alanların analizinde işlem yükü daha fazla olacağından bu yöntem ile yapılan çözümlerde daha uzun süreye ihtiyaç duyulacağı açıktır. Sınır elemanları metodunda problem bölgesinin büyük olması ekstra işlem gerektirmediği için bu metot açık alan olarak ifade edilen problemlerde kullanılabilir.

Uygulamalar gerçekleştirilirken, belirtilen yöntemlerle problem çözümü için gerekli bilgiler göz önüne alındığında, sınır elemanları yöntemi ile problem çözmek için sadece sınırdaki elemanların koordinatları ve sınır şartları yeterli iken, sonlu elemanlar yönteminde bunlara ek olarak alanın bölümlenmesi gerekmektedir.

Sınır elemanları ile sınırdaki değerler bulunduktan sonra istenen herhangi bir iç nokta için skaler potansiyel dağılımı hesaplanabilir. Sonlu elemanlarda ise potansiyel hesaplanacak iç noktalar alan bölümlenirken belirtilmelidir.

\section{Sonuçlar}

$\mathrm{Bu}$ çalışmada MEMS plakası dışında oluşan manyetostatik potansiyel analiz edilmiştir. Analiz işleminde sınır elemanları yöntemi kullanılarak Laplace problemi çözülmüştür. Sınır elemanları yönteminin başarısını belirlemek amacıyla aynı problem analitik ve sonlu elemanlar yöntemi ile çözülerek elde edilen sonuçlar karşılaştırılmıştır.

Analiz işlemi için Matlab ortamında genel amaçlı yeni bir program geliştirilmiştir. Tasarlanan program ile iki boyutlu problem bölgesinin, alan koordinatlarının, sınırların tanımlanması ve eleman uzunluğunun belirlenmesiyle otomatik olarak sonlu elemanlar ve sınır elamanları yöntemleri için çözüm yapılabilmektedir.

Yapılan uygulamalarda yöntemlerin eleman sayıları, çözüm aşamaları ve çözüm süreleri değerlendirildiğinde, sınır elemanları yönteminin iki boyutlu manyetostatik alan problemi çözümünde daha başarılı olduğu tespit edilmiştir. Sınır elemanları yöntemiyle elde edilen sonuçların, sonlu elemanlar metoduna göre daha az hatalı olduğu ve analitik çözüm sonuçlarına oldukça yakın olduğu görülmüştür.

Şekil 2 incelendiğinde sınır elemanları yöntemi ile manyetostatik alan dağılımının daha düzgün olduğu, SEM hata dağılımının daha homojen olduğu görülmüştür. Şekil 3'te sınır elemanları yönteminin 
eleman sayılarının çözüme etkisi incelenmiş, artan eleman sayısına karşılık hata oranının düştüğü tespit edilmiştir.

Şekil 1'de modellenen problemin çözümünde sonlu elemanlar metoduna göre daha başarılı olan sınır elemanları metodunun, MEMS sensörlerin algılama veya etkilenme mesafelerinin belirlenmesinde önerilebilir olduğu kanaatine varılmıştır. Geliştirilen yeni program bu tür cihazların daha iyi bir tasarıma sahip olmalarına katkı sunabilir.

\section{Kaynaklar}

Brebbia, C. A., and Poljak, D., 2005. Boundary element methods for elektrical engineers (Series: Advances in electrical engineering and electromagnetics), Vol. 4, ISBN:1-84564-033-0, WIT press, Southampton Boston, A.B.D, 92-94.

Ding, X., Jia, J., Gao, Y., Li, H., 2017. Mechanical and Electrical Noise in Sense Channel of MEMS Vibratory Gyroscopes. Sensors, vol. 17 (10), 1-21.

Dorfmann, L., and Ogden, R.W., 2014. Nonlinear Theory of Electroelastic and Magnetoelastic interactions. Springer Science \& Business Media, ISBN 978-1-46149596-3, New York, A.B.D, 24-31.

Eshraghia, I., and Dag, S., 2018. Domain-boundary element method for elastodynamics of functionally graded Timoshenko beams. Computers and Structures, vol. 195, 113-125.

Frangi, A., 2009. A BEM technique for free-molecule flows in high frequency MEMS resonators. Engineering Analysis with Boundary Elements, vol. 33, 493-498.

Gürdal, O., 2015. Elektromanyetik alan teorisi. Bursa Orhangazi Üniversitesi Yayınları, Bursa, 277-279.

Jog, C. S., and Kunal, D. P., 2016. A hybrid finite element strategy for the simulation of MEMS structures. International Journal For Numerical Methods In Engıneerıng, vol. 106, 527-555.

Matthew, N. O. S., 2001. Numerical techniques in electromagnetics, Library of Congress Cataloging-inPublication Data, Second Edition, by CRC Press LLC, ISBN 0-8493-1395-3, New York, A.B.D, 14-21.

Mukherjee, S., Telukunta, S., Mukherjee, Y. X., 2005. BEM modeling of damping forces on MEMS with thin plates. Engineering Analysis with Boundary Elements, vol. 29, 1000-1007.

Partridge, P. W., Brebbia, C. A., Wrobel L. C., 1992. The dual reciprocity boundary element method, Computational Mechanics Publications, Co-published with Elsevier Applied Science, ISBN 1-85166-700-8, Southampton Boston, A.B.D, 11-66.

Rodriguez-Tembleque, L., Buroni, F. C., Sáez, A., 2015. 3D BEM for orthotropic frictional contact of piezoelectric bodies. Comput Mech., vol. 56, 491-502.

Yıldırım S., 1999. Yüksek gerilimli sistemlerde elektrik alanlarının sınır elemanları yöntemi yardımıyla incelenmesi, Doktora Tezi, Fırat Üniversitesi, Fen Bilimleri Enstitüsü, Elâzığ, 125.

Zhang, W. M., Yan, H., Peng, Z. K., Meng, G., 2014. Electrostatic pull-in instability in MEMS/NEMS: A review. Sensors and Actuators A, vol. 214, 187-218.

Zozulya, V. V. and A. Saez, 2014. High-order theory for arched stru ctures and its application for the study of the electrostatically actuated MEMS devices. Archive of Applied Mechanics, vl. 84, 1037-1055. 